\title{
Strong Ground Pressure Mechanism and Control at the Longwall Top Coal Caving with a Single Key Stratum in Goaf
}

\author{
Ke Yang, ${ }^{1,2,3,4,5}$ Xiaolou Chi $\mathbb{D}^{1,3,4,5}$ Wenjie Liu, ${ }^{1,3,4,5}$ Litong Dou, ${ }^{1,3,4,5}$ and Zhen Wei ${ }^{1,3,4,5}$ \\ ${ }^{1}$ State Key Laboratory of Mining Response and Disaster Prevention and Control in Deep Coal Mines, \\ Anhui University of Science and Technology, Huainan, Anhui 232001, China \\ ${ }^{2}$ Institute of Energy, Hefei Comprehensive National Science Center, Hefei, Anhui 230031, China \\ ${ }^{3}$ Key Laboratory of Mining Coal Safety and Efficiently Constructed by Anhui Province and Ministry of Education, \\ Anhui University of Science and Technology, Huainan, Anhui 232001, China \\ ${ }^{4}$ National \& Local Joint Engineering Research Center of Precision Coal Mining, Anhui University of Science and Technology, \\ Huainan, Anhui 232001, China \\ ${ }^{5}$ School of Energy and Safety, Anhui University of Science and Technology, Huainan, Anhui 232001, China \\ Correspondence should be addressed to Xiaolou Chi; chixiaolou@163.com
}

Received 30 May 2020; Revised 20 July 2020; Accepted 4 August 2020; Published 24 August 2020

Academic Editor: Xianjie Hao

Copyright (C) 2020 Ke Yang et al. This is an open access article distributed under the Creative Commons Attribution License, which permits unrestricted use, distribution, and reproduction in any medium, provided the original work is properly cited.

\begin{abstract}
A strong ground pressure in the multiseam environment manifested by rib spalling and roadway deformation at the fully mechanized working face was assessed by a comprehensive combination of field measurements, physical simulations, and theoretical analysis for two coal seams in the Buertai Coal Mine in China. A structural model of overlying stratum collapse at the working face with the key stratum breaking instability was proposed, the mechanism of strong ground pressure at the longwall top coal caving working face with a single key stratum in goaf was identified, and respective control countermeasures were developed. The latter implied the directional hydraulic fracturing for supporting the key stratum-surrounding rocks, which effectively reduced the cyclic weighting intensity and weighting interval in the working face with a single key stratum in the goaf. The working face cyclic breaking interval was assessed at $30 \mathrm{~m}$. After the key stratum collapse, soft rocks underwent synergistic deformation and a cutting-type failure. The goaf effect on the hydraulic support resistance in the fully mechanized working face was assessed, and cutting blocks from the overlying stratum collapse were identified as the main sources of strong ground pressure.
\end{abstract}

\section{Introduction}

Coal consumption in China accounted for $59.0 \%$ of the total energy consumption in 2018, which makes the issues of safe and cost-efficient coal mining quite topical. One of the coal mining hazards is that, under coal-forming conditions, hard strata overlying the working face increase their ground pressure and are prone to collapse. Moreover, as the mining height increases, the overlying strata undergo extensive migration and hard strata exert even a more conspicuous and complex impact on the working face $[1,2]$. In particular, it was revealed that hard rocks in the overlying strata usually control the breaking and migration of the local strata, while the size and breaking mode of broken blocks have a decisive impact on the intensity of ground pressure manifestation. Many scholars have studied the breaking-related disastertriggering pattern in light of the breaking features and movement mode of the key strata (hard rocks). The effects of cutting structures from the key cantilever beam and the O-type breaking failure of the key strata on the ground pressure manifestation at the working face were analyzed [3-7]. The above studies formed the basis of the strata control theory. However, due to the coal seam enrichment conditions, multiseam coal beds are usually present in the strata and affect their load distribution. Therefore, load transfer mechanisms under different coal pillar widths during multiseam mining were also extensively investigated. The relationship between the height of the transmissive 
fracture belt and coal seam spacing was established, and the dynamic disaster occurrence mechanism under the influence of mining-induced stress at the working face was identified [8-14]. The design of rock support system under rockburst condition was proposed by Kaiser and Cai [15]. However, quite a few studies were focused on the key strata between the seams in multiseam mining or on the collapse features of the overlying strata with synergistic breaking. This paper analyzes the problem of strong ground pressure at the longwall top coal caving (LTCC) working face in the goaf using a comprehensive combination of field measurements, physical simulations, and theoretical analysis. The collapse of the overlying stratum during the extraction of the working face is studied in detail. The mechanism of strong ground pressure manifestation at the working face with a single key stratum between the seams in the lower goaf area is identified. Based on the directional hydraulic fracturing technology [16-21], the fracture scheme for hard rocks is proposed, which has lucrative technical and economic prospects. The results obtained provide theoretical and technical guidance for safe extraction of coal mines under similar engineering and geological conditions.

\section{Project Overview}

2.1. Geological Conditions and Mining Layout. The Buertai Coal Mine is located in the southeast of Ordos City, Inner Mongolia Autonomous Region of China. At the working face 42017 of the Buertai Coal Mine, the coal seam 4-2\# is the main extractable seam with a burial depth of 339-460 m, thickness of $6.5 \mathrm{~m}(0.90-7.68 \mathrm{~m})$, the dip angle of $1-3^{\circ}$, and working face width of $300 \mathrm{~m}$. The lithologic features of the coal seam, roof, and floor are listed in Table 1 . The coal seam 2-2\# overlying the coal seam 4-2\# with a distance of $65 \mathrm{~m}$ has a thickness of $0.82-5.80 \mathrm{~m}$ and burial depth of $212-360 \mathrm{~m}$. Both seams have simple structures and well field profiles, as well as stable horizons. The longwall top coal caving (LTCC) method is applied to the working face, with a mining height of $3.5 \mathrm{~m}$ and a caving height of $3 \mathrm{~m}$. Thus, the mining-tocaving ratio is $1: 0.86$, and the average daily advance speed is $10 \mathrm{~m} / \mathrm{d}$. Based on the drill column at the working face 42107 and the key stratum theory $[22,23]$, the 22 m-thick siltstone between the two seams is identified as the key stratum. The geographic location of the working face and the mining layout are shown in Figure 1.

2.2. Ground Pressure Behavior. Figure 2 shows the field measurement data on ground pressure distribution. The first weighting interval of the working face 42107 is about $100 \mathrm{~m}$, and the first cyclic weighting interval is about $30 \mathrm{~m}$. ZFY21000/25/39D two-column cover-type caving hydraulic supports are used for the working face 42107. The opening pressure of the safety valve of the supports is about $46 \mathrm{MPa}$. When the working face 42017 is mined at $130 \mathrm{~m}$ from the setup entry, the support working resistance at the working face rises to $50-52 \mathrm{MPa}$, as shown in Figure 2. At this moment, the safety valve of the supports opens, and there is a severe rib spalling at the working face. The floor vibrates, and the shearer bounces. Such strong ground pressure manifestations, as roadway floor heave and deformation in the segments with advanced support, occur (Figure 3), which jeopardize the coal mining operation and safety. To ensure the subsequent extraction safety of the working face, one needs to clarify the occurrence mechanism of strong ground pressure and to develop effective control countermeasures against its hazardous manifestations.

\section{Mechanical and Similar Physical Models of the Overlying Stratum Breaking}

3.1. Mechanical Model of the Key Stratum Breaking Interval. As shown in Figure 1, there is a $22 \mathrm{~m}$-thick key stratum between coal seams 4-2\# and 2-2\#. According to the key stratum theory, the key stratum physical-mechanical properties control the cyclic breaking interval. After the tensile stress in a cross section exceeds its tensile strength value, microcracks start to propagate within the key stratum, and their coalescence into macrocracks finally results in the key stratum breaking and collapse. The stress state before the breaking and rotary instability of the key stratum can be reduced to a pure bending of a cantilever beam, as shown in Figure 4 , where $M$ is the bending moment, $\mathrm{kN} / \mathrm{m} ; q$ is the distributed compressive stress, $\mathrm{MPa} h$ and $b$ are the rectangular key stratum thickness and width, respectively, m; $y_{\max }$ is the maximum roof suspension distance, $\mathrm{m}$.

The relationship between the tensile strength and breaking interval of the key stratum can be derived as follows. The maximum tensile stress $\sigma_{\max }$ and maximum bending moment $M$ are linked as

$$
\sigma_{\max }=\frac{M h}{2 l_{\mathrm{z}}},
$$

where $h$ is the beam thickness and $l_{z}$ is the moment of inertia of the rectangular cross section with respect to axis $Z, \mathrm{~m}^{4}$. This implies that the maximum normal stress in a rectangular cantilever beam in pure bending occurs at the furthest position from the neutral axis. Values of $M$ and $l_{\mathrm{z}}$ are derived as follows, using the same definitions as in Figure 4:

$$
\begin{aligned}
& M=\int_{0}^{y_{\max }} q y \mathrm{~d} y, \\
& l_{\mathrm{z}}=\frac{b h^{3}}{12} .
\end{aligned}
$$

By substituting formulas (2) and (3) into (1), the relationship between the cyclic breaking interval of the key stratum and its tensile strength is obtained:

$$
y_{\max }=h \sqrt{\frac{\sigma_{t}}{3 q}},
$$

where $\sigma_{t}$ is the tensile strength of the key stratum, MPa.

3.2. Breaking Interval of the Key Stratum. According to formula (4), lower key stratum tensile strength values correspond to smaller values of the maximum suspension roof 
TABLE 1: Lithologic features.

\begin{tabular}{lccc}
\hline Rock formation & Lithology & Thickness $(\mathrm{m})$ & Lithologic characteristics \\
\cline { 2 - 4 } & Siltstone & 8.0 & Gray, silty structure, semihard, homogeneous bedding, and quartz-based composition \\
Overburden & Sandy mudstone & 12.0 & Gray, argillaceous structure, and semihard \\
& 2-2\# coal & 3.5 & Black, blocky structure, weak bituminous sheen, and small amount of pyrite \\
Key stratum & Sandy mudstone & 19.0 & Gray, argillaceous structure, semihard, and coal-bearing wire \\
Overburden & Siltstone & 22.0 & Gray, silty structure, hard, homogeneous bedding, and quartz-based composition \\
Coal seam & Sandy mudstone & 24.0 & Gray, argillaceous structure, and semihard \\
Floor & Sandy mudstone & 5.0 & Black, blocky structure, and weak bituminous sheen \\
\hline
\end{tabular}

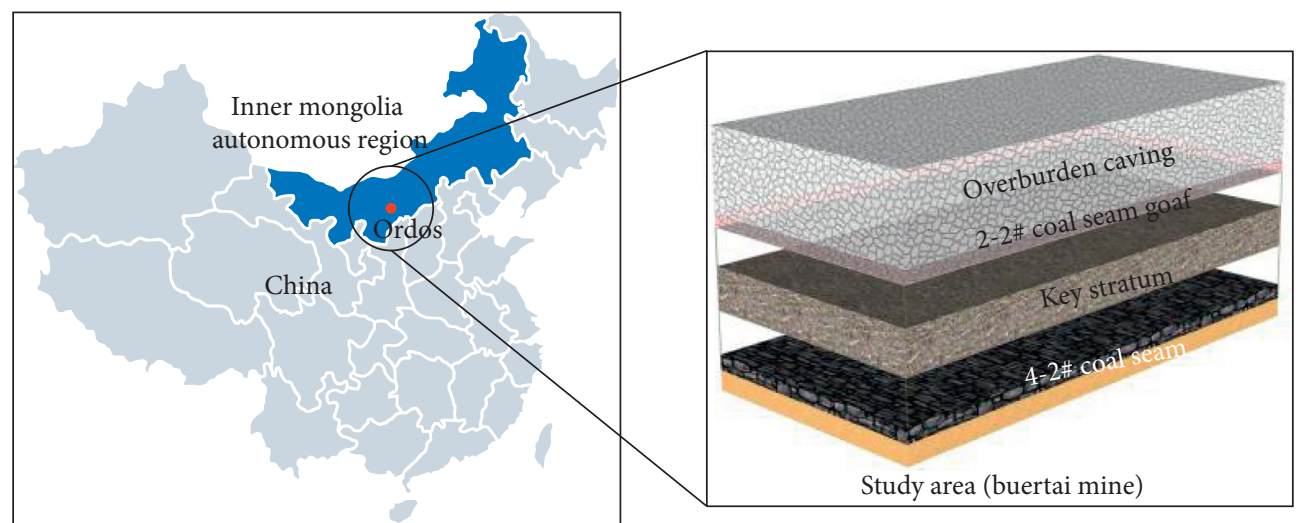

Figure 1: Mine location and working face layout.

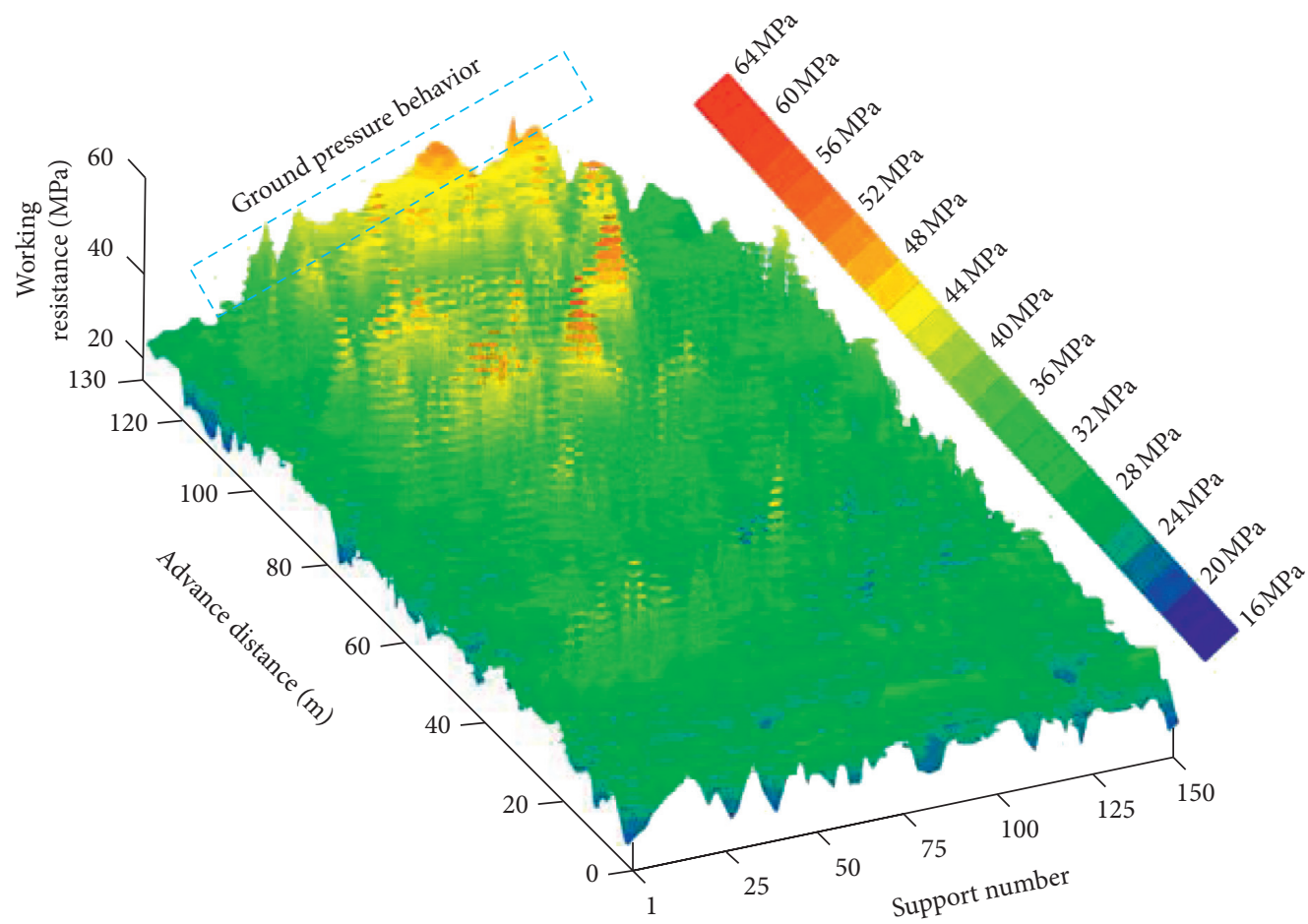

FIGURE 2: Morphology of borehole walls at different heights.

distance. During the advancing of the working face, a certain roof suspension occurred due to excessively large tensile strength of the key stratum. When the ultimate caving interval was reached in the key stratum, the latter broke, and there was the synergistic breaking of the soft rocks above it. After breaking, the rock strata load was transferred to 


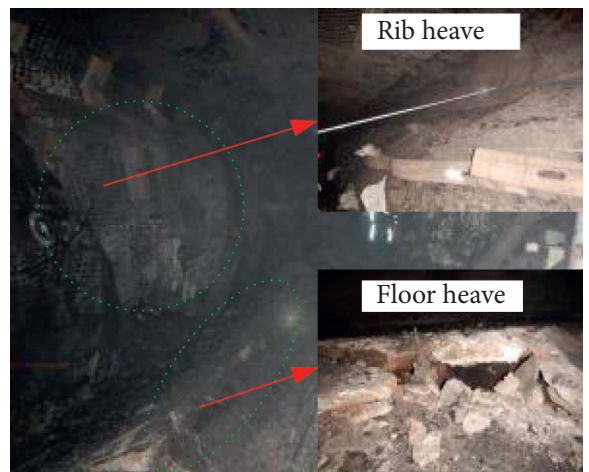

(a)

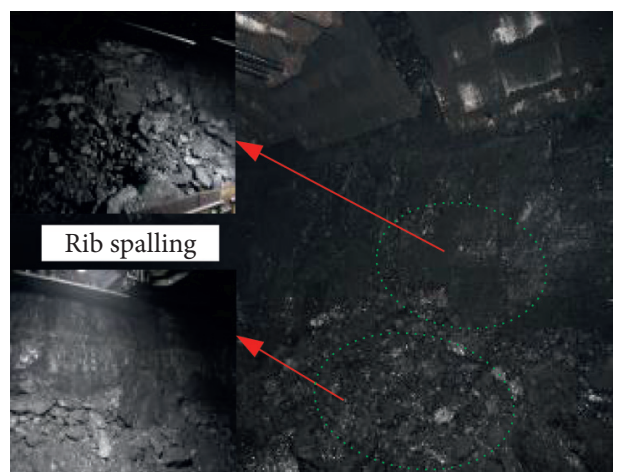

(b)

FIgURE 3: Strong ground pressure manifestations.

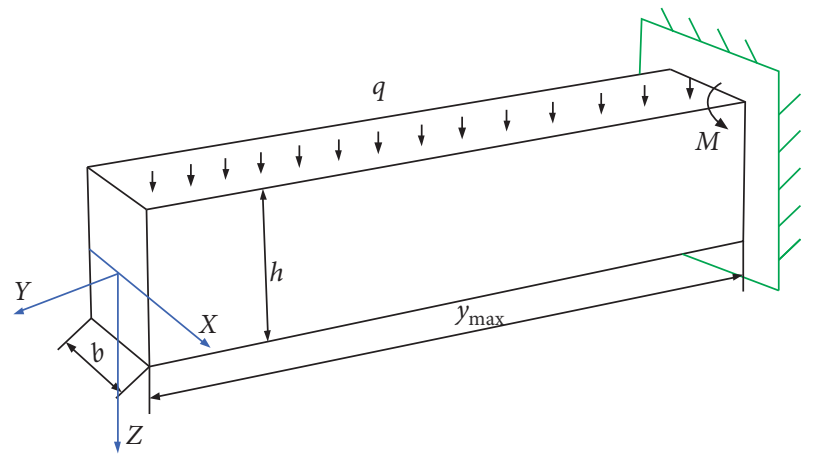

Figure 4: Mechanical model of a cantilever beam pure bending.

supports and coal bodies. The larger the caving interval of the key stratum, the larger the load acting on the supports.

According to the engineering and geological conditions of the working face 42107, the key stratum thickness was $22 \mathrm{~m}$, its tensile strength was $5.4 \mathrm{MPa}$, and the load exerted by the overlying stratum on the key stratum was 1.0 MPa. Using formula (4), the cyclic breaking interval of the key stratum was assessed as $29.5 \mathrm{~m}$.

\section{Similar Physical Simulation Test}

4.1. The Similar Physical Model. The similar physical model adopted the burial depth, thickness, and mining-to-caving ratio of the coal seam $4-2 \#$ of $460 \mathrm{~m}, 6.5 \mathrm{~m}$, and $1: 0.86$, respectively. In situ coal samples were collected by core drilling and used to fabricate cylindrical specimens for mechanical tests. Considering the discontinuity of rock materials, the joint length and continuity factor were set to 0.7 . The mechanical parameters of the coal seam 4-2\# roof and floor rocks are listed in Table 2.

The geometric similarity ratio $C_{D}$ between the simulation and field-measured parameters was set to $1: 100$. The similarity ratios of the volumetric weights of rocks and coal were $C_{\gamma \text {-Rock }}=1: 1.56$ and $C_{\gamma \text {-Coal }}=1: 1$, respectively. Based on a large number of tests and simulations, the ground pressure similarity theory was developed $[24,25]$, which implies the following similarity ratios of model stresses, elastic moduli, loads, and time.
According to the similarity theory, the following relationship exists between the physical model and geological prototype:

$$
C_{\sigma}=C_{\gamma} C_{D}
$$

where $\sigma$ is stress and $C_{\sigma}$ is the stress similarity ratio; $\gamma$ is the bulk density; $C_{\gamma}$ is the bulk density similarity ratio; $D$ is defined as length; and $C_{D}$ is the geometric similarity ratio.

In addition,

$$
C_{D}=C_{\delta} C_{\varepsilon},
$$

where $\delta$ is the displacement; $C_{\delta}$ is the displacement similarity ratio; $\varepsilon$ is the strain; and $C_{\varepsilon}$ is the strain similarity ratio.

Finally,

$$
C_{E}=C_{\sigma} C_{\varepsilon},
$$

where $E$ is the elastic modulus and $C_{E}$ is the elastic modulus similarity ratio.

Similar physical simulations also use such parameters as tensile and compressive strength values $\left(\sigma_{t}\right.$ and $\left.\sigma_{c}\right)$, cohesive force $(c)$, internal friction angle $(\beta)$, Poisson's ratio $(v)$, and friction coefficient $(\mu)$.

Insofar as parameters of the physical model are equal to those of the geological prototype, the similarity ratios of strain, internal friction angle, friction coefficient, and Poisson's ratio are equal to unity:

$$
\begin{aligned}
C_{\varepsilon} & =1, \\
C_{\beta} & =1, \\
C_{\mu} & =1, \\
C_{v} & =1 .
\end{aligned}
$$

Formulas (5)-(8) yield the following equality:

$$
C_{\sigma}=C_{E}=C_{c}=C_{\sigma_{c}}=C_{\sigma_{t}} .
$$

For the above values of $C_{\gamma \text {-Rock }}=1: 1.56$ and $C_{\gamma \text {-Coal }}=1: 1$, we get the following stress and elastic modulus similarity ratios:

$$
C_{\sigma}=C_{E}=C_{\gamma} C_{D}=156
$$


TABle 2: Physical-mechanical parameters of coal rocks and mix ratios of rock similar materials.

\begin{tabular}{|c|c|c|c|c|c|c|c|c|c|}
\hline \multirow[b]{2}{*}{ Name } & \multirow{2}{*}{$\begin{array}{l}\text { Strata } \\
\text { thickness } \\
\quad(\mathrm{m})\end{array}$} & \multirow{2}{*}{$\begin{array}{c}\text { Tensile } \\
\text { strength } \\
(\mathrm{MPa})\end{array}$} & \multirow{2}{*}{$\begin{array}{c}\text { Elastic } \\
\text { modulus } \\
(\mathrm{GPa})\end{array}$} & \multirow[b]{2}{*}{$\begin{array}{c}\text { Cohesion } \\
(\mathrm{MPa})\end{array}$} & \multicolumn{2}{|c|}{ Compressive strength } & \multicolumn{2}{|c|}{ Bulk density } & \multirow{2}{*}{$\begin{array}{l}\text { Mix ratio } \\
\text { Sand: } \\
\text { gypsum: } \\
\text { lime }\end{array}$} \\
\hline & & & & & $\begin{array}{c}\text { Prototype } \\
(\mathrm{MPa})\end{array}$ & $\begin{array}{l}\text { Model } \\
(\mathrm{MPa})\end{array}$ & $\begin{array}{c}\text { Prototype } \\
\left(\mathrm{kg} / \mathrm{m}^{3}\right)\end{array}$ & $\begin{array}{c}\text { Model } \\
\left(\mathrm{kg} / \mathrm{m}^{3}\right)\end{array}$ & \\
\hline $\begin{array}{l}\text { Sandy } \\
\text { mudstone }\end{array}$ & 50.0 & 1.57 & 6.34 & 3.6 & 32.63 & 0.21 & 2100 & 1350 & $7: 7: 3$ \\
\hline Siltstone & 8.0 & 4.31 & 10.52 & 5.4 & 86.34 & 0.55 & 2550 & 1640 & $9: 5: 5$ \\
\hline $\begin{array}{l}\text { Sandy } \\
\text { mudstone }\end{array}$ & 12.0 & 1.57 & 6.34 & 3.6 & 32.63 & 0.21 & 2100 & 1350 & $7: 7: 3$ \\
\hline $2-2 \#$ coal & 3.5 & 1.25 & 5.44 & 2.8 & 10.78 & 0.07 & 1300 & 1300 & $10: 5: 5$ \\
\hline $\begin{array}{l}\text { Sandy } \\
\text { mudstone }\end{array}$ & 19.0 & 1.57 & 6.34 & 3.6 & 32.63 & 0.21 & 2100 & 1350 & $7: 7: 3$ \\
\hline Siltstone & 22.0 & 4.31 & 10.52 & 5.4 & 86.34 & 0.55 & 2550 & 1640 & $9: 5: 5$ \\
\hline $\begin{array}{l}\text { Sandy } \\
\text { mudstone }\end{array}$ & 24.0 & 1.57 & 6.34 & 3.6 & 32.63 & 0.21 & 2100 & 1350 & $7: 7: 3$ \\
\hline 4-2\# coal & 6.5 & 1.25 & 5.44 & 2.8 & 10.78 & 0.07 & 1300 & 1300 & $10: 5: 5$ \\
\hline $\begin{array}{l}\text { Sandy } \\
\text { mudstone }\end{array}$ & 5.0 & 1.57 & 6.34 & 3.6 & 32.63 & 0.21 & 2100 & 1350 & $7: 7: 3$ \\
\hline
\end{tabular}

Then, the load similarity ratio is

$$
C_{F}=C_{\gamma} C_{D}^{3}=1.56 \times 10^{6}
$$

The time similarity ratio is

$$
C_{t}=\sqrt{C_{D}}=10
$$

Using the obtained relation between stress and elastic modulus $C_{\sigma, E}=1: 156$, the physical-mechanical parameters of the stratum under similar simulation were determined, and the initial mix ratios of similar materials were determined from the similar theory [26, 27]. Materials used for similar simulations included fine sand with the particle diameter range of $0.25-0.35 \mathrm{~mm}$, lime, and gypsum. In order to obtain the appropriate elastic modulus of the material for similar simulation, a large number of mechanical tests were performed for the collected specimens. The mix ratios of rock similar materials are listed in the last column of Table 1. First, the initial mix ratios of similar materials were preset. Then, weighted mixing was performed for similar materials (fine sand, lime, and gypsum), which were used to prepare standard columnar specimens. After curing for seven days, these specimens were subjected to mechanical tests. The final mix ratios of similar materials were determined after screening and comparative analysis.

The specification of the similar simulation device was as follows: length $\times$ width $\times$ height $=3000 \mathrm{~mm} \times 400 \mathrm{~mm} \times$ $2000 \mathrm{~mm}$. Fine sand was used as aggregate, lime and gypsum were used as a cementing agent, and water was used as a bonding agent. Based on the enrichment status of the working face 42107 in the Buertai Coal Mine, the model specification was as follows: length $\times$ width $\times$ height $=3000 \mathrm{~mm}$ $\times 400 \mathrm{~mm} \times 1500 \mathrm{~mm}$. The laying thickness of the coal seam 2-2\# was $35 \mathrm{~mm}$, and that of the overlying stratum of the coal seam 2-2\# was $700 \mathrm{~mm}$. The laying thickness of the coal seam 4-2\# was $65 \mathrm{~m}$, and that of the stratum between coal seams 2-2\# and 4-2\# was $650 \mathrm{~mm}$; the laying thickness of the floor of the coal seam $4-2 \#$ was $50 \mathrm{~mm}$. In the simulation experiment, the advancing distance along the orientation of the working face was $2200 \mathrm{~mm}$; the distances from the model left and right boundaries to the setup entry and coal seam stop mining line were both equal to $400 \mathrm{~mm}$. To achieve uniform loading, a multifunction adjustable physical simulation loading device was installed above the testing device, which partially compensated the gravity-induced load of the overlying stratum by the imposed load $0.05 \mathrm{MPa}$. There are 5 measuring lines of displacement arranged in the physical model. The physical model is depicted in Figure 5.

The time similarity ratio was the ratio of time periods required for excavations in the physical model and the actual operation at the working face. Since the roof movement is considerably affected by the extraction speed of the working face, the ground pressure manifestation pattern should change dramatically with the extraction speed variation at the working. Therefore, the time similarity ratio was used to determine the time needed for excavation in the simulation model. Based on the time and geometric similarity ratios, each day of excavation at the real working face corresponds to $2.4 \mathrm{~h}$ of excavation in the physical model. The $3 / 8$ working schedule is adopted in the Buertai Coal Mine, with two shifts per day. To be specific, every shift is responsible for excavation for $50 \mathrm{~mm}$ in the physical model (excavation for $5 \mathrm{~m}$ in the actual working face), with two shifts per day. That is, the working face in the model advanced by $100 \mathrm{~m}$ per $2.4 \mathrm{~h}$, while that at the actual working face advanced by $10 \mathrm{~m}$ per $24 \mathrm{~h}$.

4.2. Breaking Characteristics of Overburden. After the excavation of the coal seam 2-2\# was completed, its overlying stratum broke, and vertical cracks formed on both sides of the goaf. There was general bending subsidence of the overlying stratum. Due to the mining-induced influence of the coal seam 2-2\#, the overall strength of the overlying stratum decreased, and the physical-mechanical properties of rocks became close to those of soft rocks, as shown in 


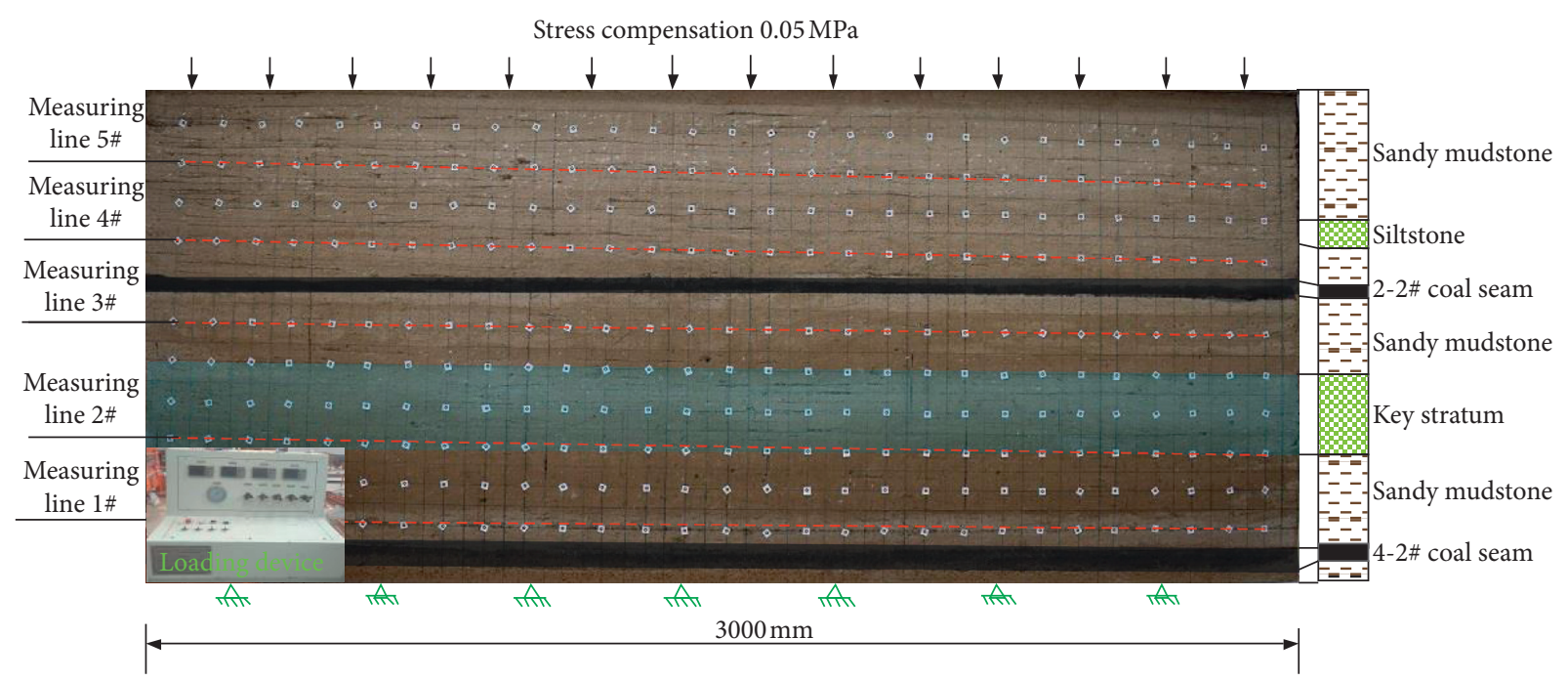

Figure 5: The similar physical model.

Figure 6(a). After the breaking of the key stratum between coal seams 2-2\# and 4-2\#, there would be a synergistic collapse of the overlying stratum of coal seam 2-2\# (equivalent to soft rocks) and key stratum. When the working face 42107 advanced to $85 \mathrm{~m}$, the lower immediate roof began to fall along with the excavation, while the immediate upper roof and key stratum remained intact. At this moment, the breaking angle of the lower immediate roof was about $52^{\circ}$, as shown in Figure 6(b).

As the working face continued to advance, the deformation of the immediate upper roof and key stratum gradually increased, and cracks began to develop. When the working face advanced to $100 \mathrm{~m}$, the $22 \mathrm{~m}$-thick key stratum broke in the rear upper part of the coal wall along the working face, and the breaking angle was about $60^{\circ}$, as shown in Figure 6(c). At this time, the working face was subject to the first weighting, which was consistent with an increase in the support load when the working face advanced to $100 \mathrm{~m}$ in Figure 2.

The bending deformation of the key stratum and bed separation space below it began to increase with the working face advance. First, transverse cracks appeared in the key stratum. Then, vertical cracks appeared in the middle of the bed separation space, exhibiting a bottom-up development. When the working face advanced to $130 \mathrm{~m}$, vertical cracks penetrated the entire key stratum. The key stratum broke, and as a result, the immediate roof, key stratum, and loadbearing layer underwent the first cutting as a whole in the rear upper part of the coal wall along the working face. The cutting angle was about $64^{\circ}$, as shown in Figure 6(d). Meanwhile, there was a synergistic movement of the key stratum and the overlying stratum of the coal seam 2-2\#, where the extraction was completed (equivalent to soft rocks).

As the working face continued to advance, after the extraction of coal seam 2-2\# was completed (equivalent to soft rocks), the key, load-bearing, and overlying strata exhibited a cyclic synergistic cutting-type breaking. The cutting position was found in the rear upper part of the coal wall along the working face. The cyclic cutting angle was close to the initial cutting angle, as shown in Figures 6(e) and 6(f). The overlying stratum underwent a cyclic cutting-type breaking as a whole. Two adjacent cutting blocks were in close contact with each other, squeezing each other and forming a hinged structure. This structure subsided slowly as the overlying stratum broke until it came into full contact with gangues in the goaf.

4.3. Displacement Characteristics of Overburden. Figure 7 shows the overburden displacement curve in the mining process of number 4-2 coal seam. It can be seen from Figure 7 that the overlying strata of number 4-2 coal seam experienced a continuous dynamic subsidence and movement process during the mining process. The subsidence trend of the overlying strata is nonlinear and the movement form is asymmetric. Specifically, when the working face is advanced to $85 \mathrm{~m}$, the immediate roof of the 4-2 coal seam will collapse, the survey line 1 will produce displacement, and the overlying strata in the goaf will have a large overhang distance. When the working face is advanced to $100 \mathrm{~m}$, the key strata $(22 \mathrm{~m}$-thick siltstone layer) fracture and collapse, the survey lines $1 \#$ and $2 \#$ produce displacement, and the subsidence trend is consistent. The working face continues to advance to $130 \mathrm{~m}, 160 \mathrm{~m}, 190 \mathrm{~m}$, and $210 \mathrm{~m}$, and the rock layer above the key strata begins to move and runs through the goaf left by the mining of the 2-2 coal seam. The subsidence trend of survey lines $1 \#$ and 2\# below the key strata is consistent, while that of survey lines $3 \#, 4 \#$, and $5 \#$ above the key layer is consistent. This indicates that after the key stratum is fractured, the soft strata under its control sink synchronously and harmonically.

According to the similar simulation results, hydraulic supports at the LTCC working face in the goaf were subjected to high loads aggravated by high dynamic load factors. The overlying stratum exhibited a cutting-type breaking. After breaking, blocks hinged to each other, forming a structure with 


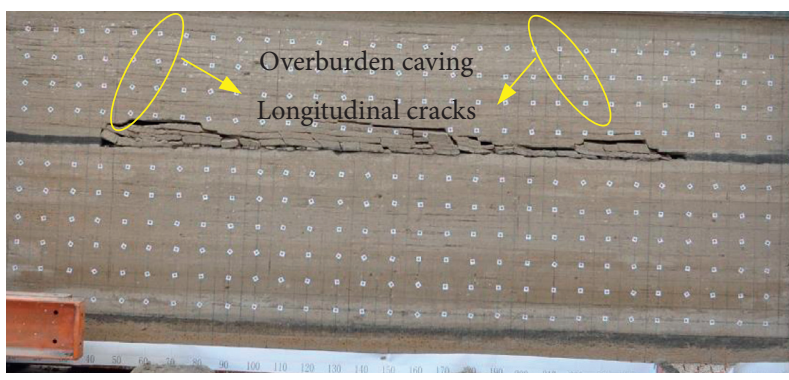

(a)

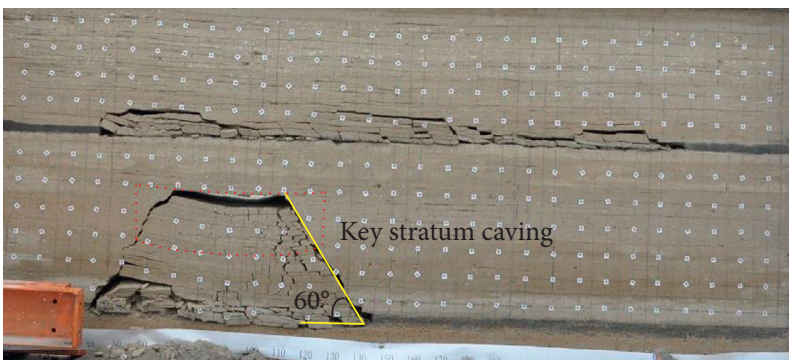

(c)

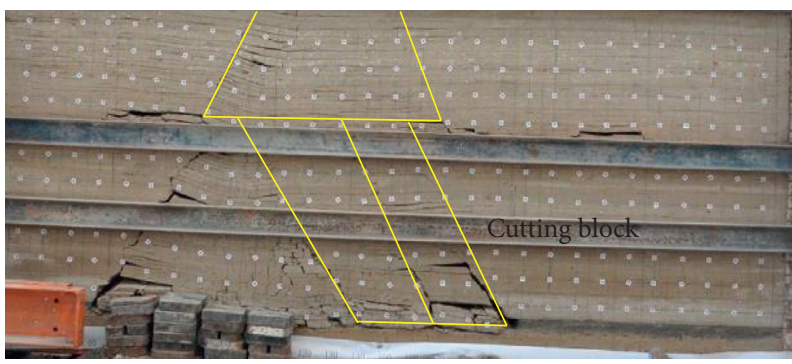

(e)

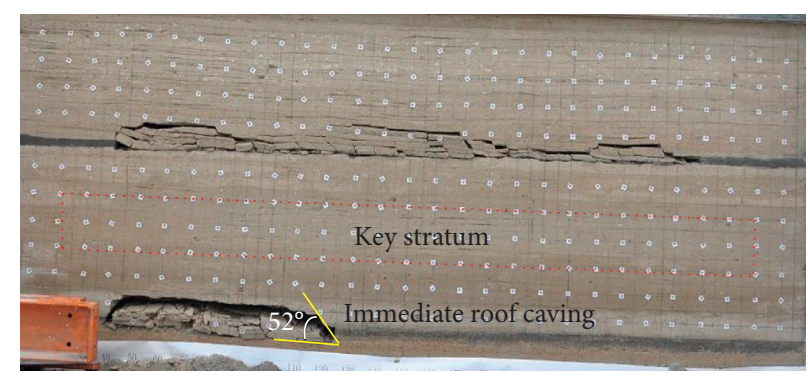

(b)

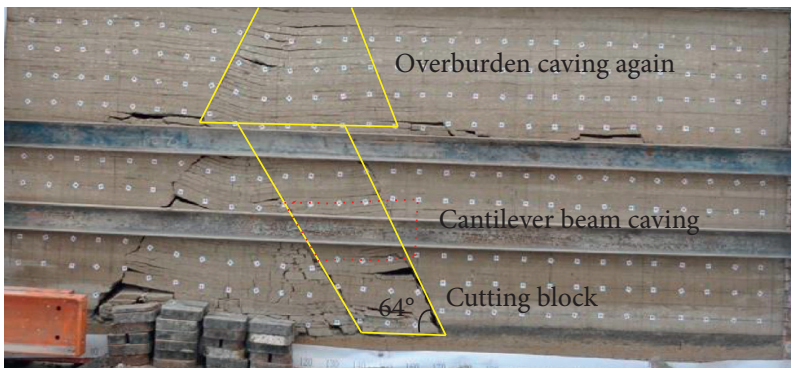

(d)

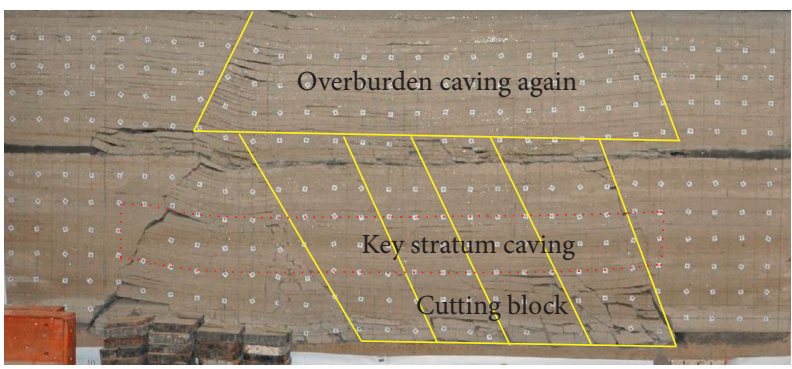

(f)

FIGURE 6: Overlying stratum breaking and instability in similar simulations: (a) extraction of the 2-2\# coal seam completed; (b) extraction of the 4-2\# coal seam at $85 \mathrm{~m}$; (c) extraction of the 4-2\# coal seam at $100 \mathrm{~m}$; (d) extraction of the 4-2\# coal seam at $130 \mathrm{~m}$; (e) extraction of the 42 \# coal seam at $160 \mathrm{~m}$; (f) completed extraction of the $4-2 \#$ coal seam.

a dominated sliding instability. Hereinafter, such structures are referred to as cutting blocks, as shown in Figure 8.

During the advancing of the working face, the cutting block interval is influenced by the key stratum breaking interval. As seen in Figure 8, the first cutting block interval (equivalent to that of the key stratum) occurred at the working face advance of $130 \mathrm{~m}$. At this time, supports of the working face withstood the load of the entire cutting block. The support working resistance rose abruptly, which was consistent with the support load increase at the working face advance of $130 \mathrm{~m}$ in Figure 2. At this time, a strong ground pressure began to manifest itself at the working face. When the working face advanced to $160 \mathrm{~m}$, the second cyclic breaking of the cutting blocks occurred. The caving interval of cutting blocks (equivalent to that of the key stratum) was $30 \mathrm{~m}$, so the similar simulation results were very close to those predicted by the mechanical model $(29.5 \mathrm{~m})$. This close correlation corroborated similar simulation accuracy.

4.4. Analysis of Support Working Resistance. The stress analysis was performed for cutting block A depicted in Figure 8, using the geometric scheme presented in Figure 9 [28].
Here, $Q$ is the compressive stress exerted by the overlying stratum of the coal seam 2-2\# (equivalent to soft rocks) on the cutting block, $\mathrm{kN}$; $T$ is the horizontal squeeze force between the cutting blocks, $\mathrm{kN}$; $G$ is the dead weight of the cutting block, $\mathrm{kN} ; F$ is friction force acting between cutting blocks, $\mathrm{kN} ; p$ is support load, $\mathrm{kN}$; $a$ is the cutting block height, $m ; L$ is the cutting interval, $m ; x$ is the distance between the application point of the support and coal wall, $m$; $\alpha$ is the cutting angle, degree. The support working resistance was calculated for the cutting block structure using the rotational equilibrium principle:

$$
\left\{\begin{array}{l}
Q\left(\frac{L}{2}+a \cot \alpha\right)+G\left(\frac{L}{2}+\frac{a}{2} \cot \alpha\right)-p x-F L \sin \alpha-T \overline{\mathrm{OD}}=0, \\
T \overline{\mathrm{OD}}=T \frac{a}{2} \sin \alpha+T\left(L+\frac{a}{2} \cot \alpha\right) \cos \alpha,
\end{array}\right.
$$

where $F=f T, f$ is the friction coefficient between blocks, and $T=\xi G, \xi$ is the horizontal squeeze factor.

The support load $p$ can be derived via formula (13) as follows: 

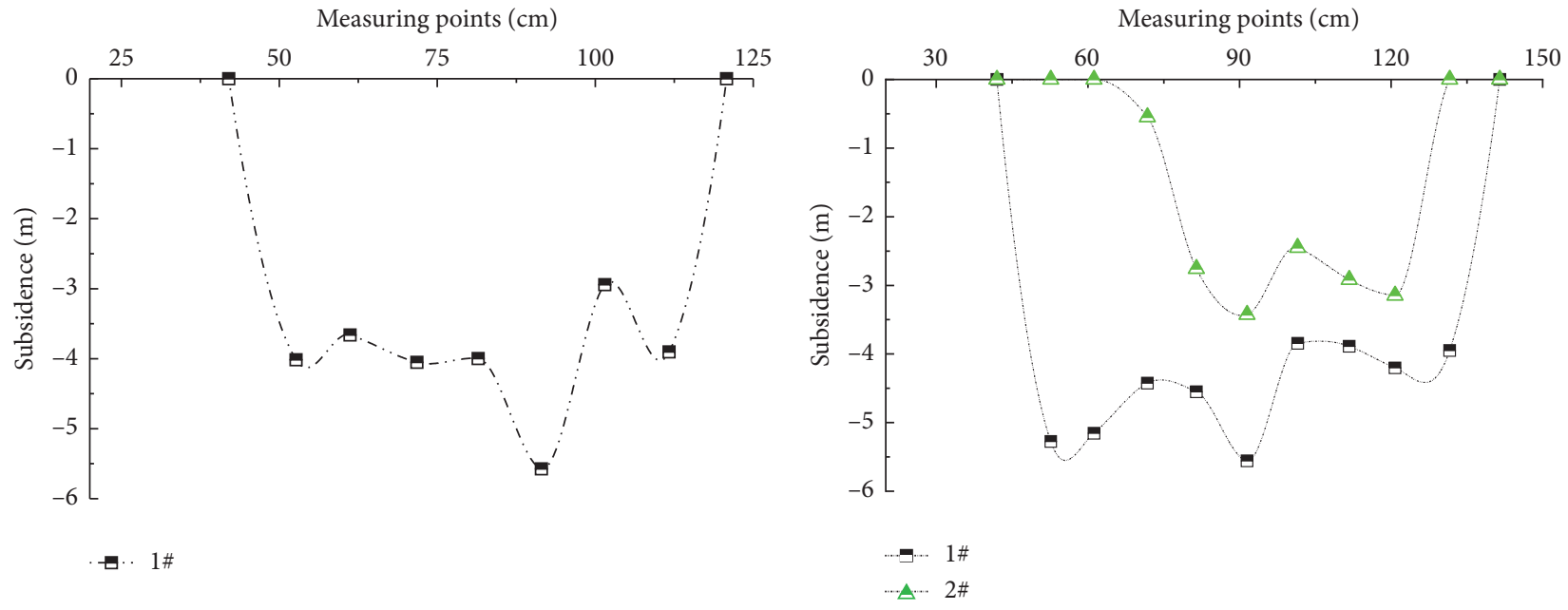

(a)
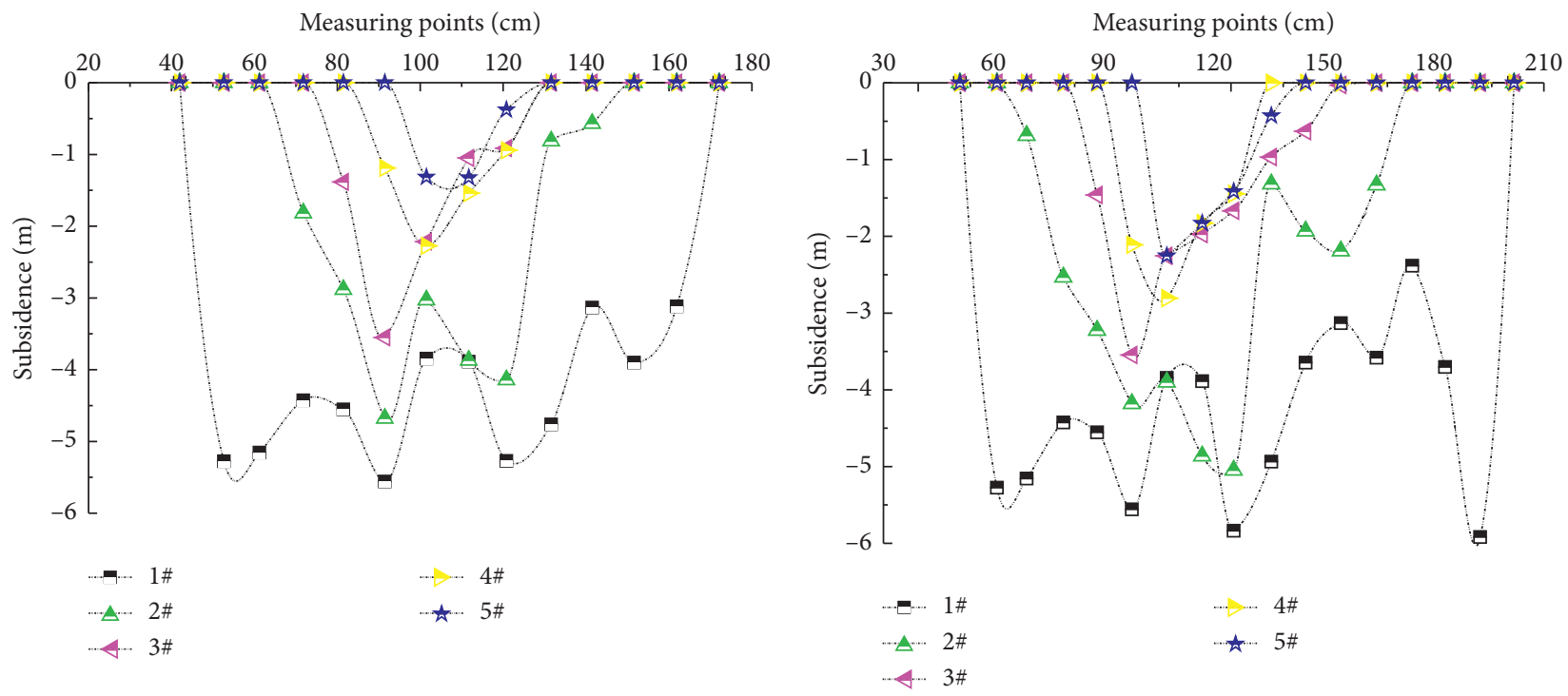

(c)
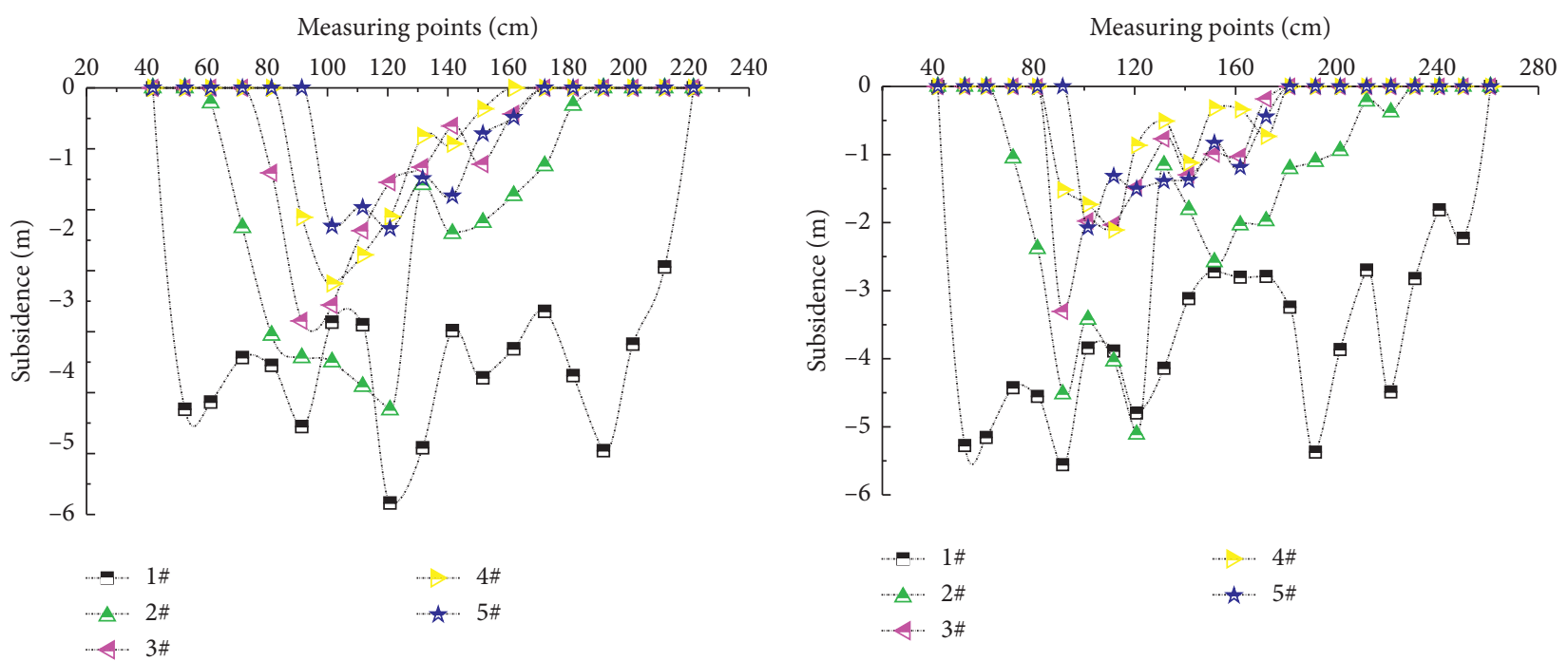

(e)

(f)

FIGURE 7: Overlying stratum subsidence in similar simulations: (a) extraction of the 4-2\# coal seam at $85 \mathrm{~m}$; (b) extraction of the 4-2\# coal seam at $100 \mathrm{~m}$; (c) extraction of the 4-2\# coal seam at $130 \mathrm{~m}$; (d) extraction of the 4-2\# coal seam at $160 \mathrm{~m}$; (e) extraction of the 4-2\# coal seam at $190 \mathrm{~m}$; (f) completed extraction of the 4-2\# coal seam. 


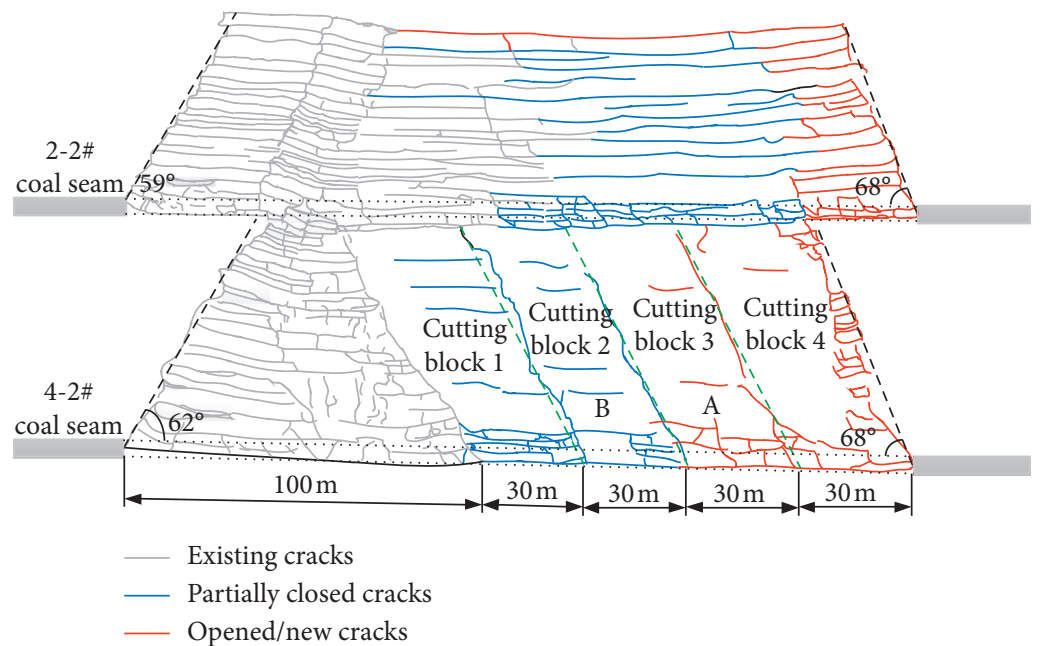

FIGURE 8: Structural sketch of the cutting blocks.

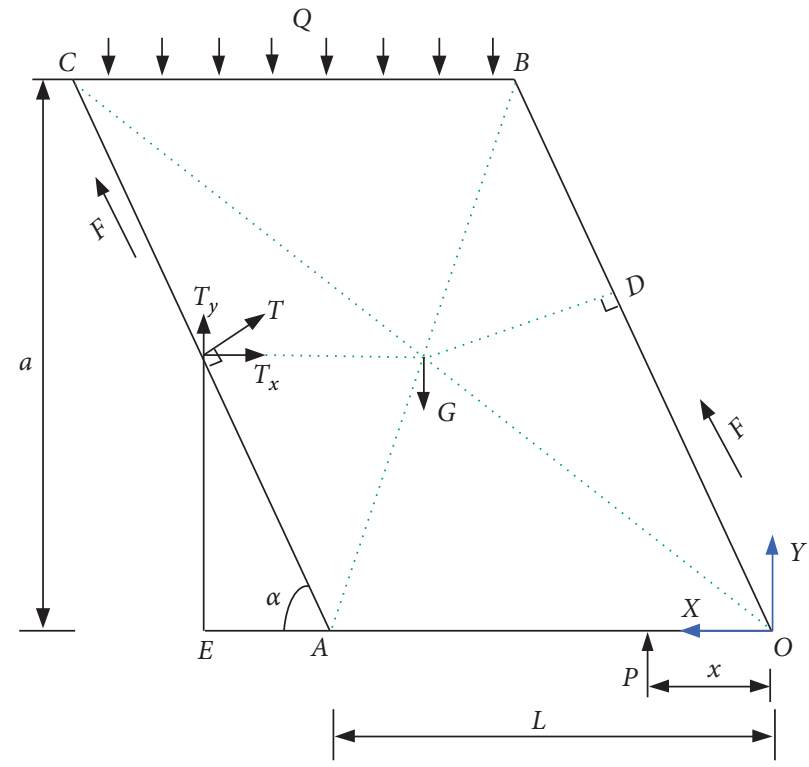

FIGURE 9: Stress analysis of cutting blocks.

$$
p=\frac{L(Q+G-2 \xi f G \sin \alpha-2 \xi G \cos \alpha)+a(2 Q \cot \alpha+G \cot \alpha-\xi G \sin \alpha-\xi G \cos \alpha \cot \alpha)}{2 x} .
$$

The width of the working face 42107 was $300 \mathrm{~m}$, and the coal seam thickness was $6.5 \mathrm{~m}$. The support model was ZFY21000/25/39D. The thickness of the cutting block was $65 \mathrm{~m}$, and the bulk density was $25 \mathrm{kN} / \mathrm{m}^{3}$. The average cyclic weighting interval was $30 \mathrm{~m}$. The distance from the application point of the resultant force of support to the coal wall was $4.5 \mathrm{~m}$. The friction factor between the rock blocks was set to 0.7 , the horizontal squeeze factor was 0.3 , and the cutting angle was $64^{\circ}$. The support working resistance via formula (14) was calculated as $p=24,000 \mathrm{kN}$, which corresponded to the internal stress of about $52 \mathrm{MPa}$ (when the diameter of the supporting column is $0.54 \mathrm{~m}$, the working resistance of the supporting column is $24 \times 106 /(3.14 \times 0.272) / 2=52 \mathrm{MPa}$. $)$.
This finding complies with measured data of ground pressure at the working face, as shown in Figure 2. Upon weighing, the support working resistance towards the cycling end was 5-52 MPa, so that the theoretical calculation results basically agreed with the field measurements.

\section{Control Countermeasures for the Strong Ground Pressure}

5.1. Hydraulic Fracturing Scheme. As analyzed above, the $22 \mathrm{~m}$-thick siltstone (key stratum) at a distance of $24 \mathrm{~m}$ from the coal seam 4-2\# was the primary stratum controlling the strong ground pressure manifestation at the working face 


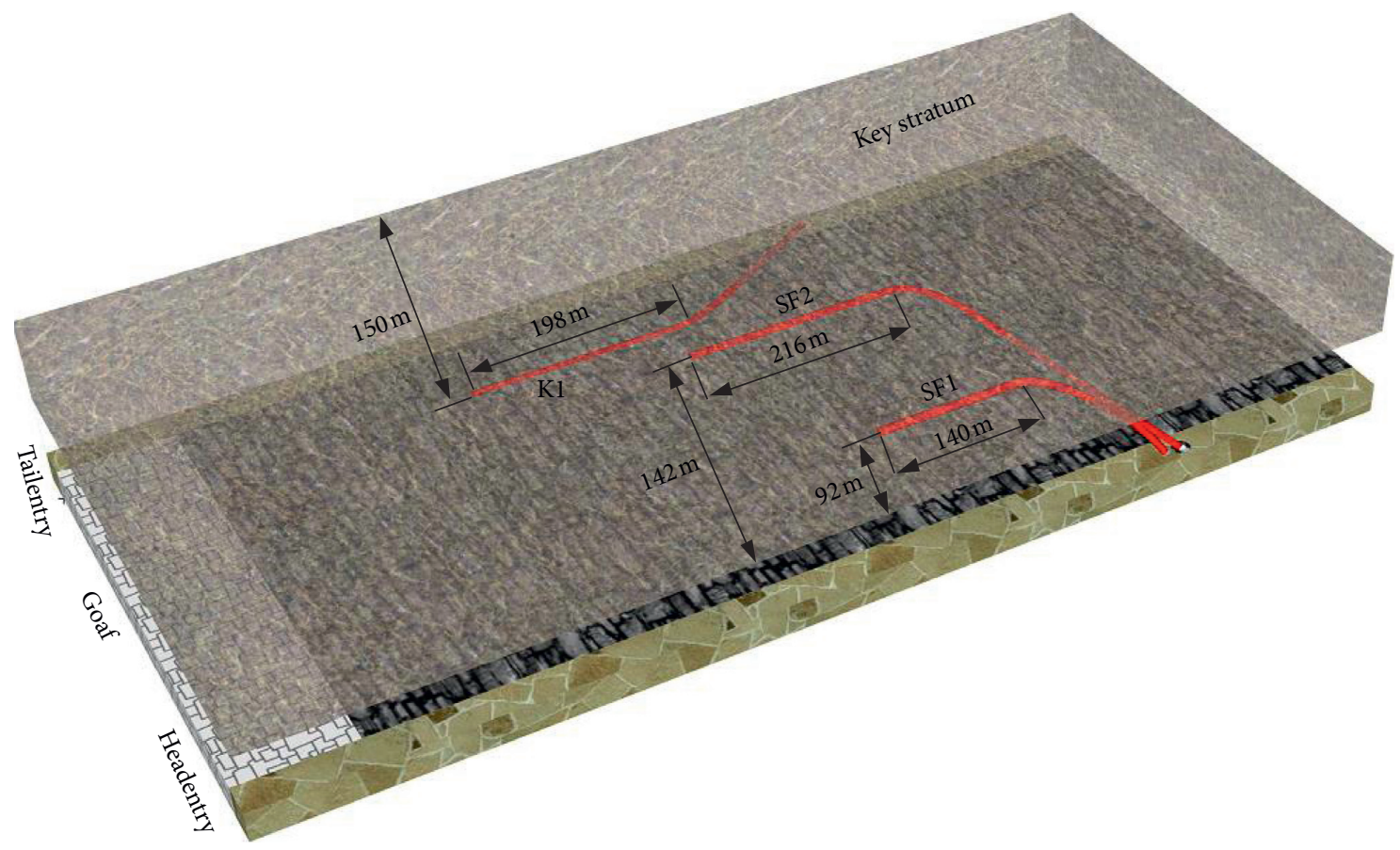

(a)

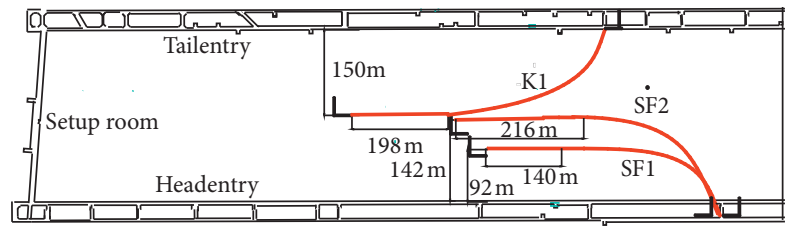

(b)

Figure 10: Positions and parameters of three boreholes: (a) stereogram; (b) profile.

42107. Therefore, the directional hydraulic fracturing was mainly applied to the key stratum between both coal seams, in order to reduce the caving interval of the key stratum and diminish the effect of cutting blocks on the ground pressure of the working face.

A detailed illustration is provided for the three directional boreholes drilled in the roadway cross section of working face 42107, as shown in Figure 10. First, the directional boreholes $\mathrm{K} 1, \mathrm{SF} 1$, and SF2 were drilled obliquely on the roof of both roadways of the working face. The direction of the drill bit was constantly adjusted so that the drill bit had just reached the middle of the key stratum when the vertical distance to the roof was $35 \mathrm{~mm}$ (the distance from the key stratum to the coal seam 4-2\# was $24 \mathrm{~m}$, and the key stratum thickness was $22 \mathrm{~m}$ ). The drilling continued horizontally. Borehole SF1 was drilled horizontally for $140 \mathrm{~m}$, and the horizontal segment of the borehole was $92 \mathrm{~m}$ from the haulage roadway of the working face 42107 . Borehole SF2 was drilled horizontally for $216 \mathrm{~m}$, and the horizontal segment of the borehole was $142 \mathrm{~m}$ from the haulage roadway of the working face 42107. Borehole K1 was drilled horizontally for $198 \mathrm{~m}$, and the horizontal segment of the borehole was $150 \mathrm{~m}$ from the ventilation roadway of the working face 42107 . At the last step, hydraulic fracturing was applied to the
$22 \mathrm{~m}$-thick key stratum to reduce the breaking interval of the key stratum.

Boreholes SF1 and SF2 were first drilled, followed by hydraulic fracturing. When the fracturing was over, the borehole $\mathrm{K} 1$ was drilled, and the fracturing was induced. Only the horizontal segment was drilled for the key stratum, to which the hydraulic fracturing was applied. The total length of three boreholes was $1132 \mathrm{~m}$, and the total length of hydraulic fracturing was $554 \mathrm{~m}$.

5.2. Application Effect. In order to assess the control effect of hydraulic fracturing of the interseam key stratum on the strong ground pressure of the working face, the data on support working resistance within the advancing distance of 560-950 m were used. At the working face 42107, a total of 125 ZFY21000/25/39D two-column cover-type caving hydraulic supports were installed. Ground pressure dynamic gauges were installed in supports, in order to continuously record the support working resistance at the working face. The measured values of support working resistance versus advancing distance are plotted in Figure 11.

The opening pressure of the safety valve at the working face 42107 was $46 \mathrm{MPa}$. Before the hydraulic fracturing of the $22 \mathrm{~m}$-thick key stratum, the support working resistance 

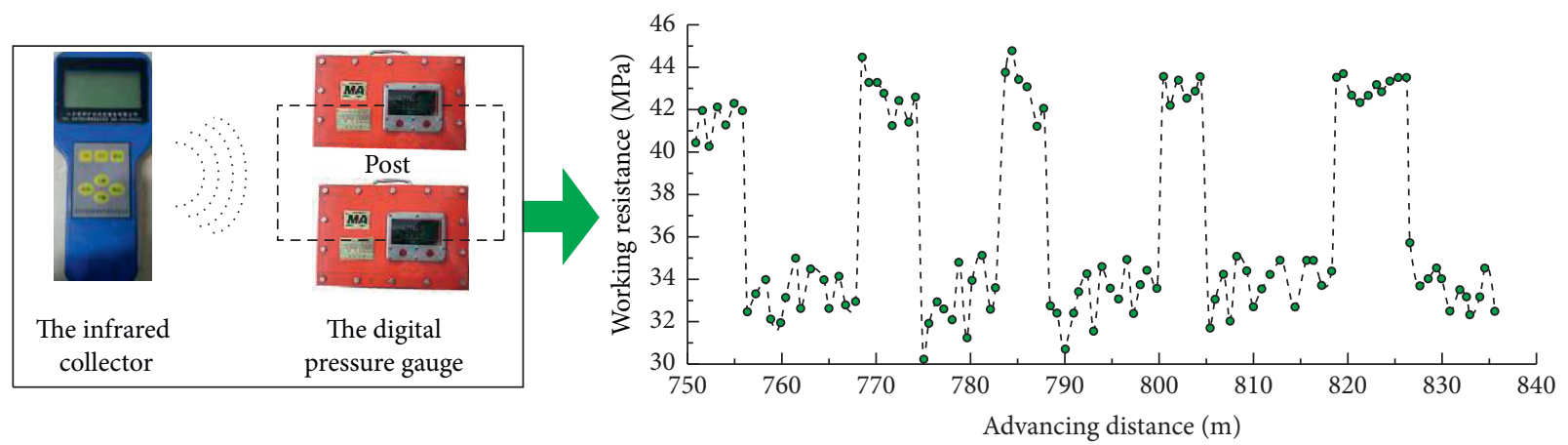

FIgURe 11: Cyclic weighting interval of the working face after the fracturing of the key stratum.

upon weighting of the working face 42017 was $50-52 \mathrm{MPa}$, and the cyclic weighting interval was about $30 \mathrm{~m}$. After hydraulic fracturing of the key stratum, the weighting interval and intensity of the working face were determined, as shown in Figure 11. After the directional hydraulic fracturing was applied to the interseam key stratum, the cyclic weighting interval of the working face 42107 was reduced to $16.9 \mathrm{~m}$, the continuous length of cyclic weighting was reduced to $4.9 \mathrm{~m}$, and the average support working resistance towards the cycling end was about $42 \mathrm{MPa}$. The results showed that after hydraulic fracturing has been applied to the $22 \mathrm{~m}$-thick key stratum, there was a significant reduction in the cyclic weighting interval, continuous length of weighting, and support working resistance towards the cycling end at the working face 42107 . This implies that strong ground pressure was efficiently controlled at the working face.

\section{Conclusions}

The results obtained made it possible to draw the following conclusions:

(1) Field measurements and physical simulations of the working face 42107 of the Buertai Coal Mine in China confirmed strong ground pressure manifestations, which included rib spalling, severe roadway deformation, high cyclic weighting intensity, and high dynamic loads. The key stratum between seams along with the overlying soft rocks after the extraction of the coal seam 2-2\# underwent synergistic sliding and breaking.

(2) The structural model for cutting blocks from the overlying stratum of the working face with the account of the key stratum breaking instability was proposed. After the key stratum collapse, there was a cutting-type breaking of soft rocks with synergistic deformation and breaking. Finally, a hinged structure of cutting blocks with a sliding instability was formed.

(3) Using the mechanical model of the key stratum weighting interval, the latter value was assessed at $29.5 \mathrm{~m}$. This estimate complied with the physical simulation result of $30 \mathrm{~m}$. Further, the formula for hydraulic support working resistance during the extraction of the working face with the consideration of cutting blocks was derived. Calculations made using the engineering and geological parameters of the working face 42107 basically agreed with the respective field measurements.

(4) The basic countermeasures against strong ground pressure manifestations at the working face should weaken thick and hard rock roofs. For this purpose, directional boreholes were drilled in the key stratum along the two roadways, and segmental hydraulic fracturing of the $22 \mathrm{~m}$-thick siltstone key stratum was applied. Both the cyclic weighting intensity and interval at the working face sharply dropped after the hydraulic fracturing. The absence of rib spalling or large roadway deformation proved that the directional hydraulic fracturing could effectively weaken the thick and hard roofs, thus reducing the intensity of ground pressure manifestation at the working face.

\section{Data Availability}

The data used for conducting classifications are available from the corresponding author upon request.

\section{Conflicts of Interest}

The authors declare that there are no conflicts of interest regarding the publication of this paper.

\section{Acknowledgments}

The authors acknowledge the financial support for this work provided by the National Natural Science Foundation of China (Grant no. 51634007) and the Graduate Innovation Fund Project of Anhui University of Science and Technology of China (2019CX1003).

\section{References}

[1] T.-b. Zhao, W.-y. Guo, Y.-l. Tan, C.-p. Lu, and C.-w. Wang, "Case histories of rock bursts under complicated geological conditions," Bulletin of Engineering Geology and the Environment, vol. 77, no. 4, pp. 1529-1545, 2017. 
[2] T.-b. Zhao, W.-y. Guo, Y.-l. Tan, Y.-c. Yin, L.-s. Cai, and J.-f. Pan, "Case studies of rock bursts under complicated geological conditions during multi-seam mining at a depth of 800 m," Rock Mechanics and Rock Engineering, vol. 51, no. 5, pp. 1539-1564, 2018.

[3] S. L. Yang, J. C. Wang, and J. H. Yang, "Physical analog simulation analysis and its mechanical explanation on dynamic load impact," Journal of China Coal Society, vol. 42, no. 2, pp. 335-343, 2017.

[4] T. Zhang, Y. X. Zhao, G. P. Zhu, S. L. Wang, and Z. H. Jiao, “A multi-coupling analysis of mining-induced pressure characteristics of shallow-depth coal face in Shandong mining area," Journal of China Coal Society, vol. 41, no. S2, pp. 287-296, 2016.

[5] H. J. Jiang, S. G. Cao, Y. Zhang, and C. Wang, "Study on the first failure and caving mechanism of key strata of shallow coal seam," Journal of Mining and Safety Engineering, vol. 33, no. 5, pp. 860-866, 2016.

[6] J. F. Ju, J. L. Xu, and Q. X. Wang, "Cantilever structure moving type of key strata and its influence on ground pressure in large mining height workface," Journal of China Coal Society, vol. 36, no. 12, pp. 2115-2120, 2011.

[7] J. F. Ju, J. L. Xu, and W. B. Zhu, "Influence of key strata cantilever structure motion on end-face fall in fully-mechanized face with super great mining height," Journal of China Coal Society, vol. 39, no. 7, pp. 1197-1204, 2014.

[8] A. M. Suchowerska, R. S. Merifield, and J. P. Carter, "Vertical stress changes in multi-seam mining under supercritical longwall panels," International Journal of Rock Mechanics and Mining Sciences, vol. 61, pp. 306-320, 2013.

[9] Q. Qu, J. Xu, R. Wu, W. Qin, and G. Hu, "Three-zone characterisation of coupled strata and gas behaviour in multiseam mining," International Journal of Rock Mechanics and Mining Sciences, vol. 78, pp. 91-98, 2015.

[10] H. Guo, L. Yuan, B. Shen, Q. Qu, and J. Xue, "Mining-induced strata stress changes, fractures and gas flow dynamics in multi-seam longwall mining," International Journal of Rock Mechanics and Mining Sciences, vol. 54, pp. 129-139, 2012.

[11] G. Si, S. Jamnikar, J. Lazar et al., "Monitoring and modelling of gas dynamics in multi-level longwall top coal caving of ultra-thick coal seams, Part I: borehole measurements and a conceptual model for gas emission zones," International Journal of Coal Geology, vol. 144-145, pp. 98-110, 2015.

[12] W. Zhang, D. Zhang, D. Qi, W. Hu, Z. He, and W. Zhang, "Floor failure depth of upper coal seam during close coal seams mining and its novel detection method," Energy Exploration \& Exploitation, vol. 36, no. 5, pp. 1265-1278, 2018.

[13] Y. Jiang, H. Wang, S. Xue, Y. Zhao, J. Zhu, and X. Pang, "Assessment and mitigation of coal bump risk during extraction of an island longwall panel," International Journal of Coal Geology, vol. 95, pp. 20-33, 2012.

[14] Y. L. Tan, X. S. Liu, J. G. Ning, and Y. W. Lu, "In situ investigations on failure evolution of overlying strata induced by mining multiple coal seams," Geotechnical Testing Journal, vol. 40, no. 2, pp. 1-14, 2017.

[15] P. K. Kaiser and M. Cai, "Design of rock support system under rockburst condition," Journal of Rock Mechanics and Geotechnical Engineering, vol. 4, no. 3, pp. 215-227, 2012.

[16] Z. L. Ge, S. H. Li, Z. Zhou, Y. Y. Lu, B. W. Xia, and J. R. Tang, "Modeling and experiment on permeability of coal with hydraulic fracturing by stimulated reservoir volume," Rock Mechanics and Rock Engineering, vol. 52, no. 8, pp. 2605-2615, 2019.

[17] J. Liu, C. Liu, and X. Li, "Determination of fracture location of double-sided directional fracturing pressure relief for hard roof of large upper goaf-side coal pillars," Energy Exploration \& Exploitation, vol. 38, no. 1, pp. 111-136, 2020.

[18] S. F. Yin, H. F. Ma, Z. H. Cheng et al., "Permeability enhancement mechanism of sand-carrying hydraulic fracturing in deep mining: a case study of uncovering coal in cross-cut," Energy Science \& Engineering, vol. 7, no. 5, pp. 1867-1881, 2019.

[19] Z. Feng, W. Guo, F. Xu, D. Yang, and W. Yang, "Control technology of surface movement scope with directional hydraulic fracturing technology in longwall mining: a case study," Energies, vol. 12, no. 18, p. 3480, 2019.

[20] Z. L. Ge, L. Zhang, J. Z. Sun, and J. H. Hu, "Fully coupled multi-scale model for gas extraction from coal seam stimulated by directional hydraulic fracturing," Applied Sciences, vol. 9, no. 21, p. 4720, 2019.

[21] P. Tan, Y. Jin, B. Hou, L. Yuan, and Z. Xiong, "Experimental investigation of hydraulic fracturing for multi-type unconventional gas co-exploitation in Ordos basin," Arabian Journal for Science and Engineering, vol. 44, no. 12, pp. 10503-10511, 2019.

[22] H. K. Han, J. L. Xu, X. Z. Wang, J. L. Xie, and Y. T. Xing, "Method to calculate working surface abutment pressure based on key strata theory," Advances in Civil Engineering, vol. 2019, Article ID 7678327, 20 pages, 2019.

[23] J. Xie and J. Xu, "The corresponding relationship between the change of goaf pressure and the key stratum breaking," Journal of Geophysics and Engineering, vol. 16, no. 5, pp. 913-925, 2019.

[24] X. P. Lai, P. F. Shan, J. T. Cao, F. Cui, and H. Sun, "Simulation of asymmetric destabilization of mine-void rock masses using a large 3D physical model," Rock Mechanics and Rock Engineering, vol. 49, no. 2, pp. 487-502, 2016.

[25] H. C. Li, Similar Simulation Test of Mine Pressure, China University of Mining and Technology Press, Xuzhou, China, 1988.

[26] G. X. Xie, J. C. Chang, and K. Yang, "Investigations into stress shell characteristics of surrounding rock in fully mechanized top-coal caving face," International Journal of Rock Mechanics and Mining Sciences, vol. 46, no. 1, pp. 172-181, 2009.

[27] X. Zhang, P. Gong, K. Wang, J. Li, and Y. Jiang, "Characteristic and mechanism of roof fracture ahead of the face in an LTCC panel when passing an abandoned roadway: a case study from the Shenghua Coal Mine, China," Rock Mechanics and Rock Engineering, vol. 52, no. 8, pp. 2775-2788, 2019.

[28] X. W. Yin, "Cutting block structure model of overburden with shallow buried coal seam and ultra-large mining height working face," Journal of China Coal Society, vol. 44, no. 7, pp. 1961-1970, 2019. 